\title{
Thickness changes in the corneal epithelium and Bowman's layer after overnight wear of silicone hydrogel contact lenses
}

\author{
Fan Lu' ${ }^{1}$ Aizhu Tao ${ }^{1 *} \mathbb{D}$, Weiwei Tao ${ }^{2}$, Xiran Zhuang $^{1}$ and Meixiao Shen ${ }^{1}$
}

\begin{abstract}
Background: To investigate thickness changes in the corneal epithelium and Bowman's layer after overnight silicone hydrogel contact lens $(\mathrm{CL})$ wear by using ultra-high resolution optical coherence tomography (UHROCT).

Methods: Eleven subjects without $C L$ wearing history were recruited for this study. An UHROCT was used to measure the thickness of the epithelium (ET), Bowman's layer (BT), stroma (ST), and total cornea (CCT) at the center of both eyes. A silicone hydrogel $\mathrm{CL}$ was inserted in the right eye of each subject, and the fellow non-CL wearing left eye served as the control. The lens was inserted at 9:30 pm and removed at 8:00 am the next morning. The subjects were evaluated at 9:00 pm (baseline), 9:30 pm (lens insertion), 10:00 pm (before sleep), 7:00 am (waking), 7:30 am, and 8:00 am (lens removal).

Results: Compared to the lens insertion level, the ET of the lens-wearing eye increased by $5.73 \%$ at eye opening $(P=0.001)$. The ET of the non- $C L$ wearing eye and the BT in both eyes did not change after overnight $C L$ wear. Compared to baseline, the CCT of the lens-wearing eye increased by $2.87 \%$ upon waking $(P=0.003)$ and recovered 30 min later $(P=0.555)$. In contrast, compared to baseline, the CCT of the non-CL wearing eye did not increase upon waking $(P=0.105)$.
\end{abstract}

Conclusions: By using UHROCT, we found that overnight $\mathrm{CL}$ wear induced different swelling responses in the various sublayers of the cornea.

Trial registration: Retrospectively registered. Registration number: ChiCTR1800015115. Registered 07 March 2018.

Keywords: Thickness, Epithelium, Bowman's layer, Overnight, Contact lens

Corneal homeostasis provides a refractive media that is essential for vision. Corneal metabolic function is reflected by the thickness of the cornea, which is maintained by the pumping function of the endothelium under normal physiological and diseased conditions [1]. The use of soft contact lenses (CLs) carries an inherent risk of reduced oxygen availability, which can result in edema of the cornea [2-4]. Eye closure results in a dramatically different environment for soft CLs than that experienced with the open eye [2]. Oxygen transmission through the conjunctiva and

\footnotetext{
* Correspondence: wztaz702@163.com

${ }^{1}$ School of Ophthalmology and Optometry, Wenzhou Medical University, 270

Xueyuan Road, Wenzhou, Zhejiang 325027, China

Full list of author information is available at the end of the article
}

limbal microvasculature and tear oxygen tension have been shown to decrease during overnight $\mathrm{CL}$ wear $[5,6]$. Hypoxia associated with corneal swelling may be a potential risk factor to make the cornea susceptible to infection. Schein et al. [7] reported that compared with daily wear, the relative risk of ulcerative keratitis for extended CL wear ranged from 3.90 to 4.21 . These findings were reconfirmed by Lim et al. [8] They found that compared with daily use, occasional overnight CL wear presented a 4-times higher risk for microbial keratitis. Therefore, compared to the open eye condition, there is a critical need to monitor corneal thickness with overnight CL wear to limit corneal swelling to a traditionally acceptable extent.

(c) The Author(s). 2018 Open Access This article is distributed under the terms of the Creative Commons Attribution 4.0 International License (http://creativecommons.org/licenses/by/4.0/), which permits unrestricted use, distribution, and reproduction in any medium, provided you give appropriate credit to the original author(s) and the source, provide a link to the Creative Commons license, and indicate if changes were made. The Creative Commons Public Domain Dedication waiver (http://creativecommons.org/publicdomain/zero/1.0/) applies to the data made available in this article, unless otherwise stated. 
New soft CL technologies and materials have been introduced to improve corneal physiology and alleviate discomfort [2, 9]. Silicone hydrogel CLs increase the supply of oxygen to the cornea as compared to conventional hydrogel lenses. Less dryness and discomfort were observed with silicone hydrogel materials than with conventional hydrogel lenses [10,11].

Corneal thickness has been analyzed by several different techniques, such as ultrasound, Scheimpflug photography, optical pachometer, confocal microscopy, and time domain optical coherence tomography (OCT) [12-14]. Total corneal swelling was reported after wearing the lenses overnight. ${ }^{2.13}$ Recently, ultra-high resolution OCT (UHROCT) has been used to calculate the thickness of each corneal layer with good repeatability $[15,16]$. Hutchings et al. evaluated the change in the thickness of the anterior, stromal, and posterior corneal laminae after eye closure and hydrogel CL wear, and they found that the thickness of the epithelium and stroma was reduced significantly with time [16]. However, subjects in that study had their eyes closed and patched for $3 \mathrm{~h}$ after CL insertion; this condition may be different from the environment after overnight CL wear. The aim of the current study was to investigate thickness changes in the corneal epithelium, Bowman's layer, stroma, and total cornea at the center of the cornea after overnight silicone hydrogel CL wear using UHROCT.

\section{Subjects and methods}

The study was approved by the human subjects review board at the Eye Hospital of Wenzhou Medical University. Each subject signed a consent form and was treated in accordance with the principles of the Declaration of Helsinki. Eleven subjects ( 6 women and 5 men, mean age: $29.4 \pm 2.4$ years, range, $27-35$ years) without a CL-wearing history were recruited for this study. The eligibility criteria included myopic diopter (D) $<-6.00 \mathrm{D}$, astigmatism < $2.00 \mathrm{D}$, and being free of any ocular or systemic disease. All the eligible participants were asked to stay overnight in the research laboratory. The temperature was maintained between $15{ }^{\circ} \mathrm{C}$ and $25{ }^{\circ} \mathrm{C}$, and the humidity was kept between 30 and 50\% in the examination room.

In this study, a custom-built UHROCT was used to assess the central corneal sublayer thickness. This system has been described in detail in a previous study [15, 17]. In brief, the central wavelength of the light source was $840 \mathrm{~nm}$, and the bandwidth was $100 \mathrm{~nm}$. The actual scan depth was approximately $2.55 \mathrm{~mm}$ in air [18], and the scan width was up to $15 \mathrm{~mm}$. The scan speed was 48 frames per second, and the axial resolution was $3 \mu \mathrm{m}$. Custom-built software (Matlab, MathWorks, Inc. Natick MA) was used to process images and create OCT longitudinal reflectivity profiles. The boundaries of the corneal sublayers were identified by the peaks of the reflectivity profiles (Fig. 1) [17]. A refractive index of 1.40 was used for each layer, and the refractive index of 1.389 was used for the total corneal thickness when translating from optical length to physical length. Three images were taken, and an average thickness was obtained.

One soft CL (PureVision; Bausch \& Lomb, Rochester, $\mathrm{NY)}$ was inserted into the right eye of each subject, and the left eye was used as a control. The base curve of the CL was $8.6 \mathrm{~mm}$, with a spherical diopter of $-3.00 \mathrm{D}$. The lens was inserted at 9:30 $\mathrm{pm}$ and removed at 8:00 am the next morning. UHROCT was performed at 9:00 pm (baseline), 9:30 pm (lens insertion), 10:00 pm (before sleep), 7:00 am (waking), 7:30 am, and 8:00 am (lens removal). Ocular comfort was evaluated by a questionnaire with a continuous scale from 0 to 50 [19]. Very poor comfort was defined as 0 , and excellent comfort was defined as 50 (Fig. 2). Ocular comfort was rated at each time point.

Data analysis was conducted with Statistical Package for the Social Sciences software (SPSS, version 13.0; SPSS, Cary, NC). On the basis of the normal epithelial thickness of $52.5 \pm 2.4$ [17], the minimum sample size to detect a 2.0 group difference with a $90 \%$ statistical power was 5 [20]. Considering the normal Bowman's layer thickness of $17.7 \pm 1.6$ [17], the minimum sample size to detect a 0.8 group difference with a $90 \%$ statistical power was 10 [20]. On the basis of normal stromal thickness of $459.1 \pm 26.8$ [17], the minimum sample size to detect a 15.0 group difference with a $90 \%$ statistical power was 8 [20]. By considering the normal total corneal thickness of $529.4 \pm 27.1$ [17], the minimum sample size to detect a 15.0 group difference with a $90 \%$ statistical power was 8 [20]. Thus, 11 cases in this study were adequate. Repeated-measures analysis of variance was used for overall statistical testing. Bonferroni post-hoc tests were used to determine whether there were differences in corneal thickness among the different visits. Adjusted $P$ values less than 0.0083 were considered significant. Data are presented as mean \pm standard deviation (SD).

\section{Results}

The average epithelial thickness of the lens-wearing right eye was $52.4 \pm 2.4 \mu \mathrm{m}$ at baseline. The epithelial thickness decreased after lens insertion $(50.6 \pm 3.1 \mu \mathrm{m})$, but this decrease was not statistically significant $(P=$ 0.027, Fig. 3). Compared to the lens insertion level, the epithelial thickness increased to $53.5 \pm 2.0 \mu \mathrm{m}$ at eye opening $(P=0.001$, Fig. 3$)$. The epithelial thickness of the non-lens-wearing left eye did not change at waking $(P>0.05$, Fig. 3). The thickness of Bowman's layer in both eyes did not change significantly after overnight $\mathrm{CL}$ wear $(\mathrm{P}>0.05$, Fig. 4). Compared to baseline, the total corneal thickness of the lens-wearing right eye increased by $2.87 \%$ upon waking the next day $(P=0.003$, Fig. 5) and recovered to baseline $30 \mathrm{~min}$ later $(P=0.555$, 

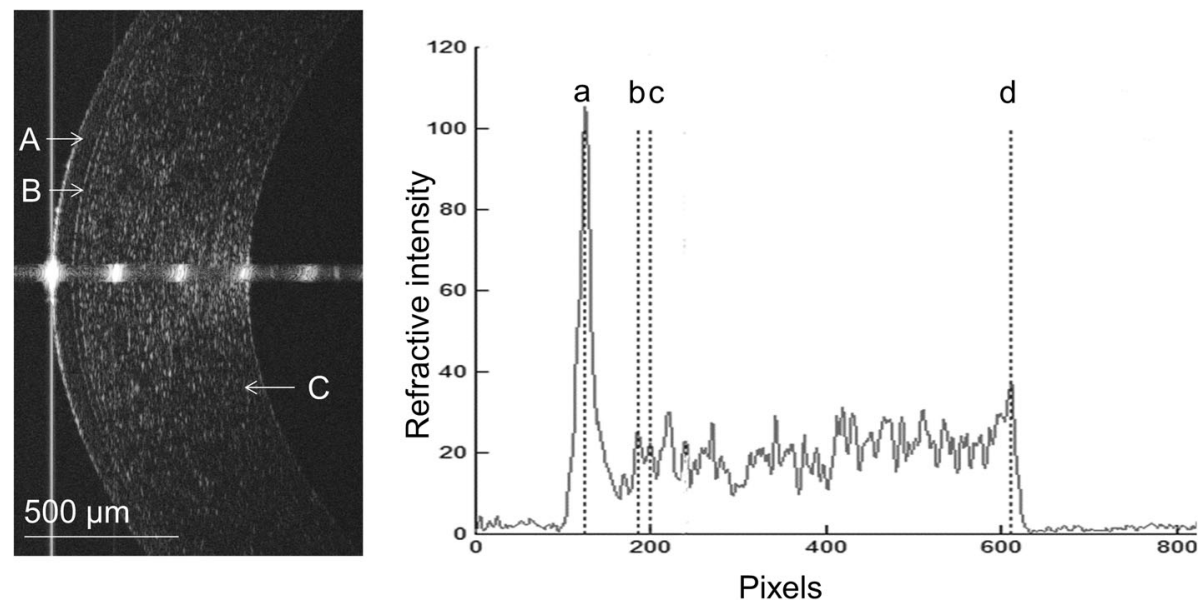

Fig. 1 Optical coherence tomography (OCT) image of one 29-year-old subject and longitudinal reflectivity profile. Left: OCT image of the cornea center at baseline. a: Epithelium; b: Bowman's layer; $\mathbf{c}$ : Stroma. Right: Longitudinal reflectivity profile after removing the strong reflectivity at the center. The distance between peaks $a$ and $b$ was the thickness of the epithelium; the distance between peaks $b$ and $c$ was the thickness of Bowman's layer; the distance between peaks $\mathrm{c}$ and $\mathrm{d}$ was the thickness of stroma; and the distance between peaks a and d was the total corneal thickness

Fig. 5). In contrast, compared to baseline, the total corneal thickness of the non-lens-wearing left eye did not increase at waking $(P=0.105$, Fig. 5$)$. The trend of stromal thickness was similar to that of total corneal thickness (Fig. 6). Ocular comfort decreased after lens insertion $(P=0.007$, Fig. 7$)$ and remained lower during CL wear (Fig. 7).

\section{Comfort questionnaire}

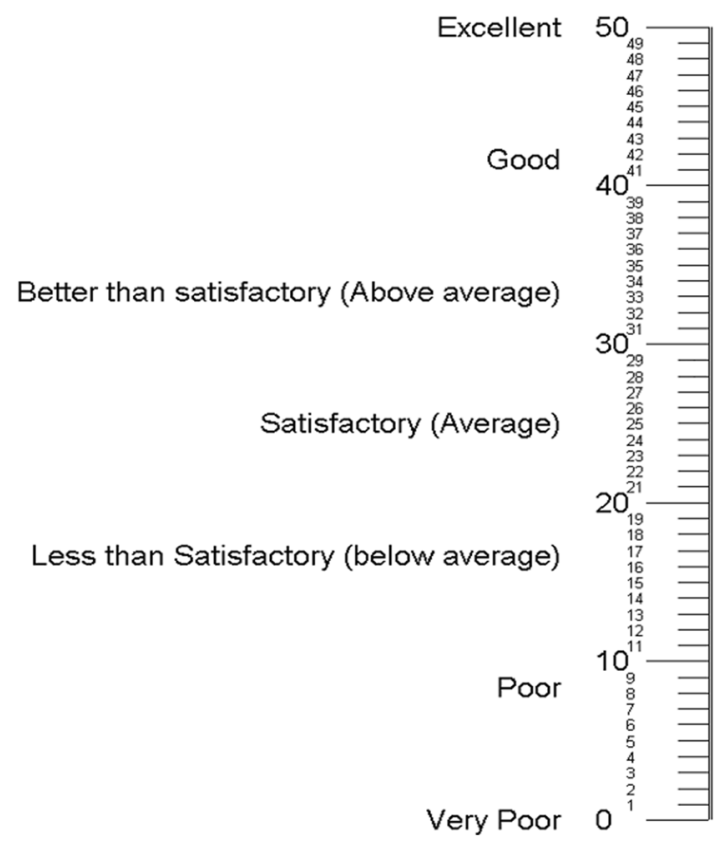

Fig. 2 A questionnaire was used to rate ocular comfort. Very poor comfort was defined as 0 , and excellent comfort was defined as 50

\section{Discussion}

The fit of soft CLs in vivo has been subjectively assessed by slit-lamp biomicroscopy in the clinic or quantified by video capture, but both methods provide limited resolution [21, 22]. Shen et al. [23] characterized the conjunctival buildup and tear film gaps of differently designed CLs; however, the clinical significance of these new parameters remains unclear. Hall et al. analyzed the corneal-scleral shape profile to predict the CL fit [24]. Our previous studies evaluated the entire CL thickness by using long scan depth OCT based on a complementary metal oxide semiconductor and a charge-coupled device camera $[25,26]$. The axial resolution was compromised with a long scan depth, and an ultra-high resolution $(\leq 5 \mu \mathrm{m})$ did not succeed in extending the scan depth OCT. Therefore, the thickness of the corneal sublayers was not analyzed in these previous studies [25, 26]. Recently, UHROCT has been demonstrated to be a feasible method of measuring the sublayer thickness of the cornea in vivo. In this study, we focused on thicknesses of separate layers of the cornea after overnight CL wear.

By using UHROCT, the epithelial and total corneal thickness at baseline in the present study was similar to that of our previous studies [15, 17]. Fonn et al. [13] used an optical pachometer,and observed that the total corneal thickness at baseline was $540 \mu \mathrm{m}$, which was in agreement with that observed in the present study. In contrast, by using time domain OCT, Wang et al. [27] observed that the measured epithelial thickness was $59.9 \mu \mathrm{m}$, which was thicker than that of the present study. By using UHROCT, Hutching et al. [16] noted that the mean epithelial thickness and total corneal thickness of 8 non-CL wearers was $58.40 \mu \mathrm{m}$ and 


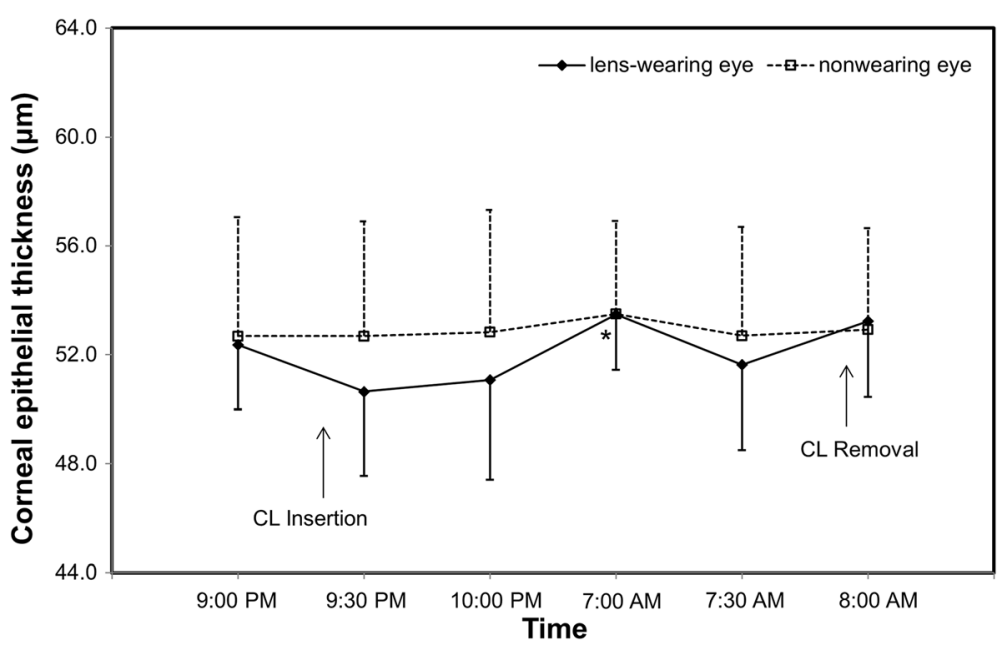

Fig. 3 Corneal epithelial thickness after overnight contact lens $(C L)$ wear. Compared to the lens insertion level, the epithelial thickness of the lens-wearing eye increased at eye opening $(P=0.001)$. The epithelial thickness of the non-CL-wearing left eye did not change at waking $(P>0.05)$.: $P<0.05$, compared with the lens insertion level

$613.91 \mu \mathrm{m}$, respectively, which were much higher than the values obtained in this study. Reasons for the discrepancy between these studies may be explained as follows: First, the demographic characteristics of the subjects of these studies, including age and ethnicity, were different. Second, instruments with different resolutions were used to acquire corneal images, and some studies used in-house-developed software for analysis. The refractive index used to convert the optical measurement to the physical measurement in these programs may be different, which may lead to overestimation or underestimation of the corneal thickness of each layer.

By using an optical pachometer, the central corneal swelling induced by the lotrafilcon A lens was found to be $2.71 \%$ [13]. Moezzi et al. used the same instrumen$t$,and observed that the percentage of central corneal swelling with the comfilcon A and lotrafilcon A lenses was 4.1 and $4.0 \%$, respectively, for an 8 -h overnight period [28]. We found the corneal swelling to be $2.87 \%$ after overnight CL wear with a material of balafilcon A; this magnitude of swelling was similar to that noted in previous studies using silicone hydrogel lenses. In contrast, as measured with a Holden-Payor pachometer, corneal swelling was found to be approximately $7.0 \%$ in symptomatic and asymptomatic CL wearers who were wearing bilateral disposable etafilcon A lenses overnight [29]. After $3 \mathrm{~h}$ of hydrogel CL wear with eye closure, the total corneal swelling was approximately $8.3 \%$ with UHROCT [16] and 13.4\% with time-domain OCT. [14]

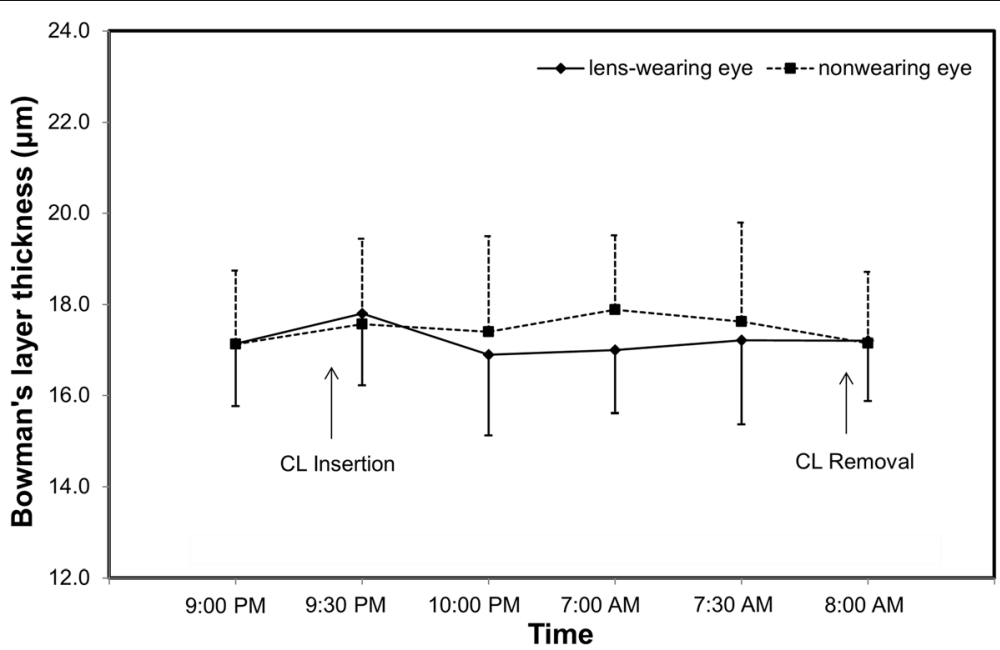

Fig. 4 Bowman's layer thickness after overnight contact lens $(\mathrm{CL})$ wear. The thickness of Bowman's layer in both eyes did not change significantly after overnight $C L$ wear $(P>0.05)$ 


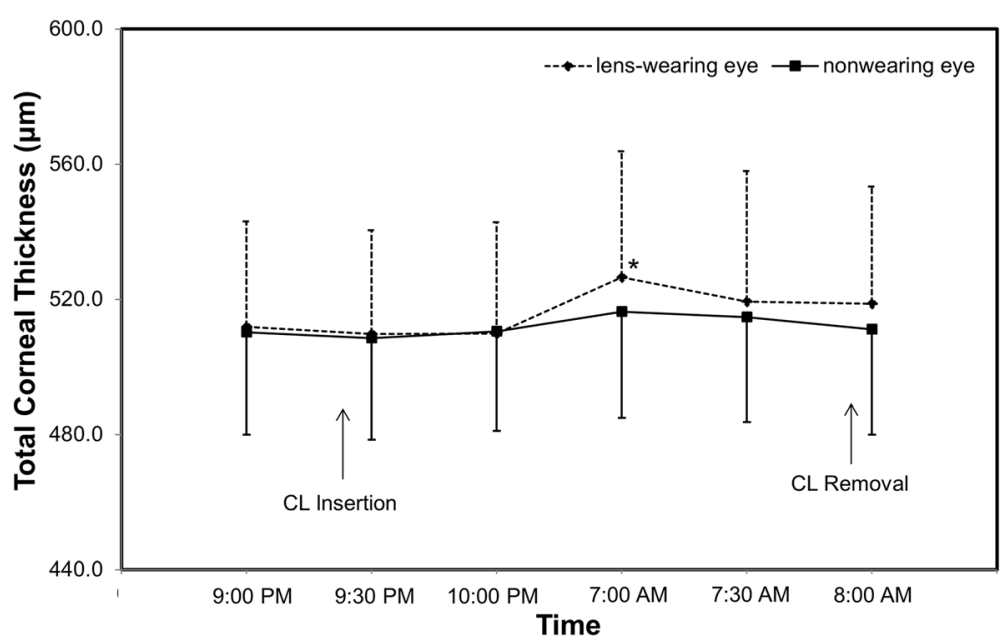

Fig. 5 Total corneal thickness after overnight contact lens (CL) wear. Compared to baseline, the total corneal thickness of the lens-wearing right eye increased at waking the next day $(P=0.003)$ and recovered 30 min later $(P=0.555)$. In contrast, the total corneal thickness of the non-CL wearing left eye did not increase at waking $(P=0.105)$. *: $P<0.05$, compared with baseline

Silicone hydrogel CLs with high oxygen transmissibility were developed to relieve hypoxia during overnight CL wear [2]; this may be the main reason that corneal health was better with silicone hydrogel than with hydrogel. In addition, corneal swelling induced by patching with eye closure for $3 \mathrm{~h}$ may be different from that induced by overnight CL wear.

The response to overnight CL wear was different in the various sublayers of the cornea. The epithelial thickness had a decreased trend immediately after lens insertion; this may be caused by the lens exerting mechanical pressure on the ocular surface. After overnight CL wear, at eye opening, corneal epithelial thickness increased by $5.73 \%$. The thickness of Bowman's layer did not change after $9 \mathrm{~h}$ of sleeping with the lenses overnight. Thus, the increase in the central corneal thickness was mainly due to the increase in the epithelial and stromal thicknesses. The swelling of the epithelial layer in the present study was similar to the swelling found after hydrogel CL wear with eye closure [16]. Compared to the stroma, the limited expansion capacity of the epithelium may have contributed to the similar expansion found in both studies. The stronger regions of the cornea are locked anteriorly and have been proposed to be less affected than the posterior sublayer when the cornea swells $[16,30]$. As we expected, the epithelium showed less swelling than the posterior lamellae. Furthermore, the stroma recovered

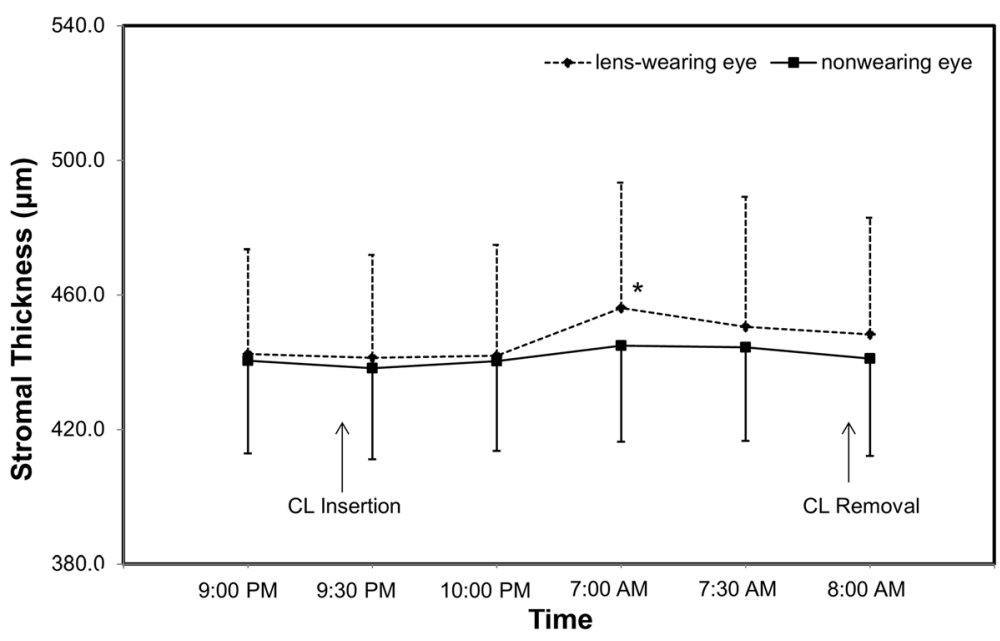

Fig. 6 Stromal thickness after overnight contact lens $(C L)$ wear. Compared to baseline, the stromal thickness of the lens-wearing right eye increased at waking $(P=0.005)$ and recovered 30 min later $(P=0.383)$. In contrast, the stromal thickness of the non-CL-wearing left eye did not increase at waking $(P=0.467)$. * $P<0.05$, compared with baseline 


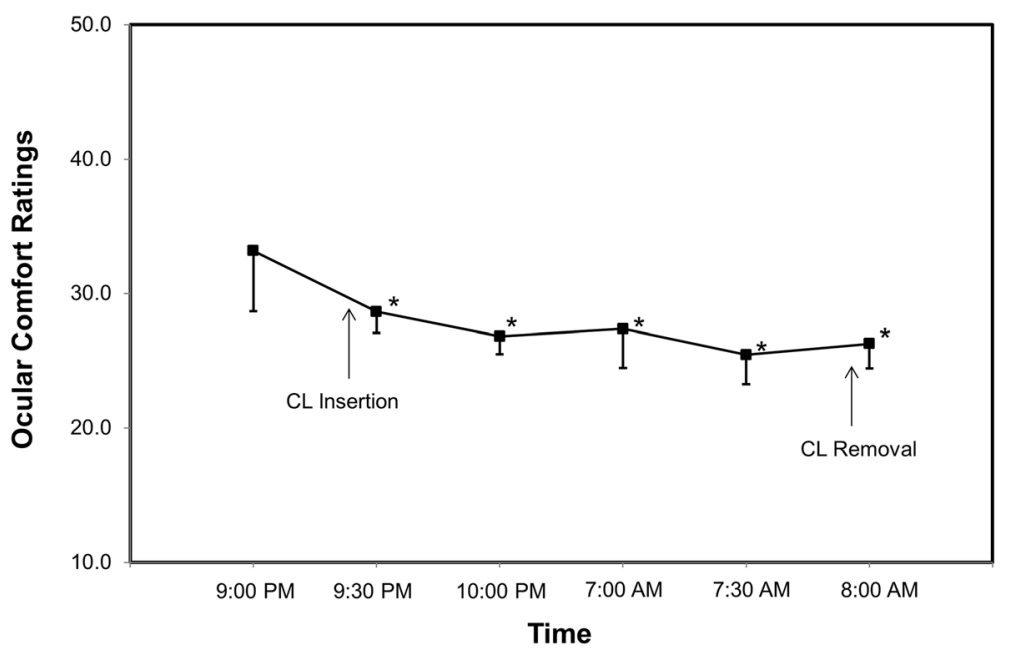

Fig. 7 Ocular comfort ratings after overnight contact lens $(C L)$ wear. Ocular comfort decreased after lens insertion $(P=0.007)$ and remained low during $C L$ wear. *: $P<0.05$, compared with baseline

to baseline levels within $30 \mathrm{~min}$ of eye opening. The corneal epithelium and endothelium are two barriers to maintain corneal transparency and hydration. Thirty minutes after the eye opening, the increased supply of oxygen to the eye led to a decrease in corneal edema and recovery of the normal corneal structure.

The response of the lens-wearing right eye was different from that of the non-lens-wearing left eye after overnight eye closure. In the present study, both CL wear and overnight eye closure induced hypoxia in the right eye, whereas the response of the left eye was mainly due to overnight eye closure. Therefore, the epithelium and stroma of the left eye did not change after overnight eye closure. As reported by Fonn et al., the corneal swelling of the lens-wearing eye can affect the swelling of the contralateral control eye [13]. Because of the possible existence of a sympathetic physiological response, the use of the contralateral non-lens-wearing eye as the control eye, as done in this study, may differ from using both eyes without lens wear as the control.

This study had some limitations. First, we focused on the corneal sublayer changes at the center of the eye in the present study. Further studies on the superior, inferior, nasal, and temporal limbus changes after overnight CL wear need to be conducted. Second, only one soft CL with the same base curve was used for all subjects in the present study. Because the ocular surface character of each subject was different, the lens fit may have been different, although all fits are acceptable in the clinic [31]. The corneal sublayer response to CLs with different lens materials, different lens designs, or different base curves needs to be investigated in future studies. Third, changes in corneal sublayer thickness after only 1 night of soft CL wear was investigated.
However, further studies with longer period of extended wear are needed to better understand the corneal effect of hypoxia after hydrogel CL and silicone hydrogel CL use.

\section{Conclusions}

In summary, by using UHROCT, we found that the swelling response induced by overnight CL wear was different in the various sublayers of the cornea.

\section{Abbreviations}

BT: Bowman's layer thickness; CCT: central corneal thickness; CLs: contact lenses; D: diopter; ET: epithelial thickness; OCT: optical coherence tomography; SD: standard deviation; ST: stromal thickness; UHROCT: ultra-high resolution OCT

\section{Acknowledgments \\ Not Applicable.}

\section{Proprietary interests}

The authors have no proprietary interest in any materials or methods described within this article.

\section{Funding}

This study was supported by the Medical Scientific Research Foundation of Zhejiang Province, China (2016KYB204), the Development Program Project Grant from Wenzhou (Y20160149), Public Project of Zhejiang Province (2017C33117). The funding organizations had no role in the design or conduct of this study.

\section{Availability of data and materials}

The datasets used and/or analyzed during the current study are available from the corresponding author on reasonable request.

\section{Authors' contributions}

Design of the study (FL, AT, XZ); data collection (AT, XZ, WT), analysis and interpretation of the data (FL, AT, WT, MS), preparation, review and approval of the manuscript (FL, AT, XZ, WT, MS). All authors read and approved the final manuscript.

\section{Ethics approval and consent to participate}

The study was approved by the human subjects review board at the Eye Hospital of Wenzhou Medical University. Each subject signed a consent form and was treated in accordance with the principles of the Declaration of Helsinki. 


\section{Consent for publication}

Not Applicable.

\section{Competing interests}

The authors declare that they have no competing interests.

\section{Publisher's Note}

Springer Nature remains neutral with regard to jurisdictional claims in published maps and institutional affiliations.

\section{Author details}

'School of Ophthalmology and Optometry, Wenzhou Medical University, 270 Xueyuan Road, Wenzhou, Zhejiang 325027, China. ${ }^{2}$ The First Affiliated Hospital of Wenzhou Medical University, Wenzhou, Zhejiang, China.

Received: 7 February 2018 Accepted: 24 October 2018

Published online: 03 November 2018

\section{References}

1. Mishima S. Clinical investigations on the corneal endothelium XXXVIII Edward Jackson memorial lecture. Am J Ophthalmol. 1992;93:1-29.

2. Steffen RB, Schnider CM. The impact of silicone hydrogel materials on overnight corneal swelling. Eye Contact Lens. 2007;33(3):115-20.

3. Ladage PM, Jester JV, Petroll WM, Bergmanson JP, Cavanagh HD. Role of oxygen in corneal epithelial homeostasis during extended contact lens wear. Eye Contact Lens. 2003;29:S2-6.

4. Wang J, Fonn D, Simpson $T L$, Jones $L$. The measurement of corneal epithelial thickness in response to hypoxia using optical coherence tomography. Am J Ophthalmol. 2002;133:315-9.

5. Holden BA, Mertz GW. Critical oxygen levels to avoid corneal edema for daily and extended wear contact lenses. Invest Ophthalmol Vis Sci. 1984;25:1161-7.

6. Bonanno JA, Stickel T, Nguyen T, Biehl T, Carter D, Benjamin WJ, et al. Estimation of human corneal oxygen consumption by noninvasive measurement of tear oxygen tension while wearing hydrogel lenses. Invest Ophthalmol. Vis. Sci. 2002:43:371-6.

7. Schein OD, Glynn RJ, Poggio EC, Seddon JM, Kenyon KR. The relative risk of ulcerative keratitis among users of daily-wear and extended-wear soft contact lenses. A case-control study. N Engl J Med. 1989;321:773-8.

8. Lim C, Carnt NA, Farook M, Lam J, Tan DT, Mehta JS, et al. Risk factors for contact lens-related microbial keratitis in Singapore. Eye. 2016;30(3):447-55.

9. Guillon M. Are silicone hydrogel contact lenses more comfortable than hydrogel contact lenses? Eye Contact Lens. 2013;39:86-92.

10. Dillehay SM, Miller MB. Performance of lotrafilcon B silicne hydroge contact lenses in experienced low-Dk/t daily lens wearers. Eye Contact Lens. 2007:33:272-7.

11. Long B, Schweizer H, Bleshoy H, Zeri F. Expanding your use of silicone hydrogel contact lenses: using lotrafilcon a for daily wear. Eye Contact Lens. 2009;35:59-64.

12. Kuerten D, Plange N, Koch EC, Koutsonas A, Walter P, Fuest M. Central corneal thickness determination in corneal edema using ultrasound pachymetry, a Scheimpflug camera, and anterior segment OCT. Graefes Arch Clin Exp Ophthalmol. 2015:253(7):1105-9.

13. Fonn D, Toit R, Simpson TL, Vega JA, Situ P, Chalmers RL. Sympathetic swelling response of the control eye to soft lenses in the other eye. Invest Ophthalmol Vis Sci. 1999;40:3116-21.

14. Wang J, Fonn D, Simpson TL. Topographical thickness of the epithelium and total cornea after hydrogel and PMMA contact lens wear with eye closure. Invest Ophthalmol Vis Sci. 2003:44:1070-4.

15. Ge L, Yuan Y, Shen M, Tao A, Wang J, Lu F. The role of axial resolution of optical coherence tomography on the measurement of corneal and epithelial thicknesses. Invest Ophthalmol Vis Sci. 2013;54:746-55.

16. Hutchings N, Simpson TL, Hyun C, Moayed AA, Hariri S, Sorbara L, et al. Swelling of the human cornea revealed by high-speed, ultrahigh-resolution optical coherence tomography. Invest Ophthalmol Vis Sci. 2010;51:4579-84.

17. Tao A, Wang J, Chen Q, Shen M, Lu F, Dubow SR, et al. Topographic thickness of Bowman's layer determined by ultra-high resolution spectral domain optical coherence tomography. Invest Ophthalmol Vis Sci. 2011;52:3901-7.
18. Ge L, Shen M, Tao A, Wang J, Dou G, Lu F. Automatic segmentation of the central epithelium imaged with three optical coherence tomography devices. Eye Contact Lens. 2012;38:150-7.

19. Dumbleton KA, Woods CA, Jones LW, Fonn D. Comfort and adaptation to silicone hydrogel lenses for daily wear. Eye Contact Lens. 2008;34:215-23.

20. Erdfelder E, Faul F, Buchner A. Gpower: a general power analysis program. Behav Res Methods Instrum Comput. 1996;28:1-11.

21. Golding TR, Bruce AS, Gaterell LL, Little SA, Macnamara J. Soft lens movement: effect of blink rate on lens setting. Acta Ophthalmol Scand. 1995;73:506-11.

22. Brennan NA, Lindsay RG, McCraw K, Young L, Bruce AS, Golding TR. Soft lens movement: temporal characteristics. Optom Vis Sci. 1994;71:359-63.

23. Shen M, Cui L, Riley C, Wang MR, Wang J. Characterizaton of soft contact lens edge fitting using ultra-high resolution and ultra-long scan depth optical coherence tomography. Invest Ophthalmol Vis Sci. 2011:52:4091-7.

24. Hall LA, Young G, Wolffsohn JS, Reliy C. The influence of corneo-scleral topography on soft contact lens fit. Invest Ophthalmol Vis Sci. 2011;52: 6801-6.

25. Tao A, Shao Y, Jiang H, Ye Y, Lu F, Shen M, et al. Entire thickness profiles of the epithelium and contact lens in vivo imaged with high-speed and highresolution optical coherence tomography. Eye Contact Lens. 2013;39:329-34.

26. Shen M, Wang MR, Wang J, Yuan Y, Chen F. Entire contact lens imaged in vivo and in vitro with spectral domain optical coherence tomography. Eye Contact Lens. 2010:36:73-6.

27. Wang J, Thomas J, Cox I, Rollins A. Noncontact measurements of central corneal epithelial and flap thickness after laser in situ Keratomileusis. Invest Ophthalmol Vis Sci. 2004;45:1812-6.

28. Moezzi AM, Fonn D, Simpson TL. Overnight corneal swelling with silicone hydrogel contact lenses with high oxygen transmissibility. Eye Contact Lens. 2006:32:277-80

29. Stapleton F, Lakshmi KR, Kumar S, Sweenev DF, Rao GN, Holden BA Overnight corneal swelling in symptomatic and asymptomatic contact lens wearers. CLAO J. 1998:24:169-74.

30. Dawson DG, Grossniklaus HE, McCarey BE, Edelhauser HF. Biomechanical and wound healing characteristics of corneas after excimer laser keratorefractive surgery: is there a difference between advanced surface ablation and sub-Bowman's keratomileusis? J Refract Surg. 2008:24:590-6.

31. Hall LA, Young G, Wolffsohn JS, Riley C. The influence of corneoscleral topography on soft contact lens fit. Invest Ophthalmol Vis Sci. 2011;52: 6801-6.

Ready to submit your research? Choose BMC and benefit from

- fast, convenient online submission

- thorough peer review by experienced researchers in your field

- rapid publication on acceptance

- support for research data, including large and complex data types

- gold Open Access which fosters wider collaboration and increased citations

- maximum visibility for your research: over $100 \mathrm{M}$ website views per year

At $\mathrm{BMC}$, research is always in progress.

Learn more biomedcentral.com/submission 